\title{
Method for cost-effective trans aortic valve replacement device prototyping
}

\author{
Angelique Oncale ${ }^{1}$, Charles Taylor ${ }^{2}$, Erika Louvier ${ }^{3}$, G.H. Massiha ${ }^{4}$ \\ 1,3,4 Department of Industrial Technology, University of Louisiana at Lafayette, United States \\ ${ }^{2}$ Department of Petroleum Engineering, Louisiana State University, United States
}

\begin{tabular}{l} 
Article Info \\
\hline Article history: \\
Received Sep 4, 2019 \\
Revised Oct 6, 2019 \\
Accepted May 14, 2020 \\
\hline
\end{tabular}

Keywords:

Aortic stenosis

Aortic valve

Computer aided design

Computer numerical control

Trans aortic valve replacement

\begin{abstract}
Trans Aortic Valve Replacement (TAVR) has offered the cardiology sector of health a new alternative to open heart surgeries which treat aortic stenosis. The technologies used by TAVR manufacturers are kept private. Our research goal was to develop a process that allows college level laboratories to fabricate their own TAVR stents in order to research new designs and methods of fabrication which may improve current TAVR practices. By creating a solid model of a stent cell design in SolidWorks, we were able to export a cutting pattern we used with a waterjet. The stent frame was then hand polished to prepare for fabric skirting and leaflet attachment. Synthetic ripstop fabric was cut using a commercial fabric cutting machine and attached to the frame using a waterproof glue. Future research entails welding techniques, improved polishing methods, and implantation into a mechanical system. This prototype could be used for TAVR related research and surgical training simulations.
\end{abstract}

This is an open access article under the CC BY-SA license.

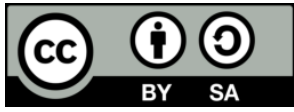

\section{Corresponding Author:}

Angelique Oncale,

Department of Industrial Technology,

University of Louisiana at Lafayette,

104 East University Avenue, Lafayette, Louisiana 70506, United States

Email: angelique.oncale1@ louisiana.edu

\section{INTRODUCTION}

Trans Aortic Valve Replacement (TAVR) is a relatively new medical procedure that has been evolving over nearly two decades as an alternative to open heart surgery for the treatment of Aortic Stenosis (AS). This disease is most prevalent in the elderly with almost 27,000 patients becoming eligible for a TAVR procedure annually [1]. The only two companies that create and sell FDA approved TAVR devices in the United States are Edwards Lifesciences and Medtronic. Their revolutionary designs have become an incredibly popular treatment option for high risk patients, and improved designs may become an option for patients with lower risk profiles or those with more complex combinations of heart diseases who were excluded from earlier trials of TAVR [2].

The treatment of aortic stenosis with valve implants became more widely used after the development of the bi-leaflet mechanical heart valve. This type of valve is still used today, however its popularity is decreasing with the rise of TAVR valves [3]. The TAVR valve's predecessor, Surgical Aortic Valve Replacement (SAVR) valves, and bi-leaflet mechanical valves both involve invasive surgeries that many high-risk patients are unable to endure. TAVR technology is our safest option for the largest population of patients but still has serious issues that need to be resolved.

The most common and persistent issue with TAVR valves are paravalvular leaks and paravalvular regurgitation. A two-year analysis of post-op TAVR implantations found that regurgitation "remained 
unchanged in $46.2 \%$ of the 143 patients studied and was worse in $22.4 \%$ " [4]. This problem is caused in large part by a difference in stent and aortic annulus sizes [5]. The current lifespan of a TAVR, 10-15 years, is one of the main reasons the technology is not being used for other medical conditions or younger patients. Valves are also not yet fully retrievable and valve-in-valve implantations reduce the annulus size, affecting hydrodynamic performance [6].

The largest hindrance to TAVR improvements is the lack of information and technology available to independent researchers. Software techniques to better size devices and predict deployment success have been developed but are unable to test their methods outside of simulation [7, 8]. Simplified devices for research have made contributions to groups seeking to validate their research in the past. In 2017, a method to create a bioprosthetic semilunar valve helped provide research-grade heart valves to independent groups [9]. This device fabrication method was used later in 2017 to simulate a paravalvular leak for repair using cardioscopic imaging [10]. The same method was used in 2019 to test autonomous robotic navigation [11]. This research can provide the same means of validation for research involving TAVR devices.

A number of issues still surround the TAVR procedure including paravalvular leaks or regurgitation, tissue and frame durability, and valve longevity $[4,5,12,13]$. These problems need to be resolved before this procedure can be expanded to a larger population. The techniques used by Edwards and Medtronic to make TAVR valves are kept private from the general public, making it difficult for researchers outside of these corporations to study alternative fabrication methods and designs which may offer a solution to common TAVR issues. Additionally, TAVR valves such as the Sapien 3 have an acquisition cost of about $\$ 32,500$ and are only sold to medical professionals for interventional use [14]. A process for fast, cost efficient prototyping of TAVR valves is needed to reflect the devices being used in the current industry and to subsequently research improvements involving the technology. Without an actual device to test on or information on its construction, there is no way to validate new developments.

The research presented here seeks to fully defines a method by which a collegiate level lab can produce balloon expandable TAVR stent prototypes. The prototype built in this study uses easily attainable materials such as stainless steel and nylon fabric resulting in a lower cost. Fabrication methods mentioned here rely heavily on computer numerical control (CNC) machines including a waterjet and a consumer fabric cutter. Contract manufacturing for waterjet cutting can be used by those without direct access to this equipment. This process can be used to prototype existing designs or be adapted for new designs. This prototyping method can be useful for comparison studies or studies involving a functioning TAVR valve.

\section{RESEARCH METHODS AND MATERIALS}

The prototype built in this study uses easily attainable materials such as stainless steel and nylon fabric resulting in a lower cost. Fabrication methods mentioned here rely heavily on computer numerical control (CNC) machines including a waterjet and a consumer fabric cutter. Contract manufacturing for waterjet cutting can be used by those without direct access to this equipment. This process can be used to prototype existing designs or be adapted for new designs.

Table 1 is showing the cell design of the TAVR stent was inspired by online images of the Sapien XT frame. The Sapien XT comes in sizes $23 \mathrm{~mm}, 26 \mathrm{~mm}$, and $29 \mathrm{~mm}$ with heights of $14.3 \mathrm{~mm}, 17.2 \mathrm{~mm}$, and $19.1 \mathrm{~mm}$ respectively [15]. Using the $29 \mathrm{~mm}$ diameter and $19.1 \mathrm{~mm}$ height, a parametric model of our frame was created in Solidworks which can be viewed in both its flat pattern form and its 3D cylindrical form. The online images showed a frame which could be divided into 3 identical sections, separated by thicker struts which are used to anchor the leaflets. The frame's geometry was specifically chosen to ensure its crimping ability; it includes small spaces at the top and bottom of each cell as well as over 400 fillets to aid in bending. The model was made using a number of variables and simple equations so that the size of the frame and its individual parts can be easily manipulated by changing the value of a single variable. This allows users to study the device in different sizes and define its features exactly to the user's requirements. The variables and equations may also be applied to different cell designs to make them parametric as well as shown in Figure 1, Figure 2, and Figure 3. 
Table 1. CAD model variables

\begin{tabular}{clll}
\hline Global Variable & Description & Value/Equation & Evaluates to \\
\hline A & Inner Diameter & $29 \mathrm{~mm}$ & $29 \mathrm{~mm}$ \\
B & Overall Length & $(((\mathrm{A} * 3.1415) / 3)-(2 * \mathrm{C})-(\mathrm{D})) / 3$ & $9.21728 \mathrm{~mm}$ \\
$\mathrm{C}$ & Strut Thickness & $0.608 \mathrm{~mm}$ & $0.608 \mathrm{~mm}$ \\
$\mathrm{D}$ & Overall Height & $1.5 \mathrm{~mm}$ & $1.5 \mathrm{~mm}$ \\
$\mathrm{E}$ & Large Cell Connector Diameter & $19.1 \mathrm{~mm}$ & $19.1 \mathrm{~mm}$ \\
$\mathrm{~F}$ & Cell Connector Length & $\mathrm{E} * 0.75$ & $14.325 \mathrm{~mm}$ \\
$\mathrm{G}$ & Cell Connector Centering & $\mathrm{E} / 2$ & $9.55 \mathrm{~mm}$ \\
$\mathrm{H}$ & Cell Distance & $\mathrm{B}+\mathrm{C}$ & $9.82528 \mathrm{~mm}$ \\
$\mathrm{I}$ & Linear Pattern Distance & $(\mathrm{B} * 3)+\mathrm{D}+(\mathrm{C} * 2)$ & $30.3678 \mathrm{~mm}$ \\
$\mathrm{~J}$ & Cell/Strut Distance & $\mathrm{C}+0.5$ & $1.108 \mathrm{~mm}$ \\
\hline
\end{tabular}

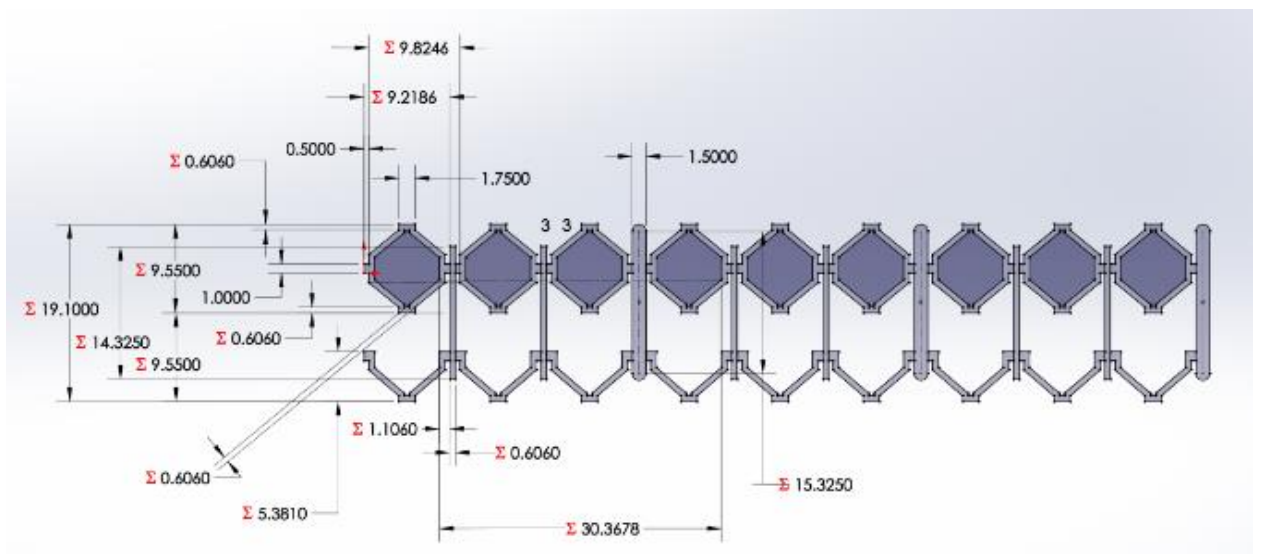

Figure 1. Full sketch of the parametric CAD model with variables

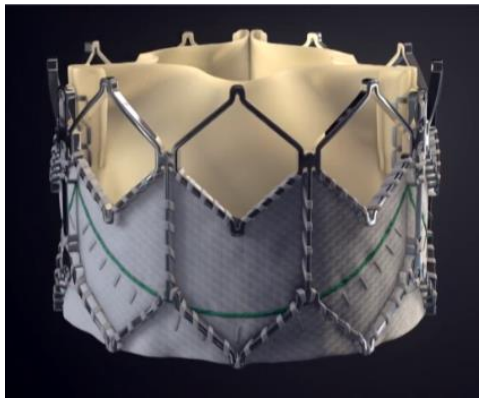

Figures 2. Reference photograph of the Sapien XT valve

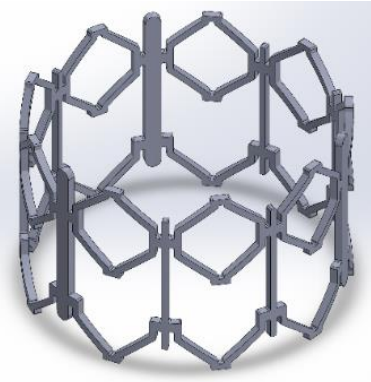

Figures 3. Parametric model in cylindrical configuration [16]

Figure 4 is showing flat pattern form was used to cut the stent frame from a $0.015 "(0.5 \mathrm{~mm})$ thick strip of 316 stainless steel using an OMAX MAXIEM 1515 abrasive waterjet. The waterjet was chosen as the frame fabrication method for many reasons. Contract waterjet cutting is significantly cheaper and more widely available to the public that 3D printing or laser cutting. Fabrication with a laser may also cause heat affected zones to become weakened; waterjets cut cold which eliminates this issue [17]. The waterjet was equipped with a MAXJET 5i nozzle and a 0.015" diameter jewel. The abrasive material used was 150 grit garnet and backed the stainless steel with hardboard and a 3" thick honeycomb Rhino Board. The jet's properties were set to 316 Stainless Steel material, 0.015" thickness, and 0.01" tool offset. The flat pattern shows strut thicknesses to be $0.606 \mathrm{~mm}$, however the tool offset allows the jet to cut tight corners needed to produce the valve's geometry and cuts material away from the struts reducing the thickness to a desired 0.5 $\mathrm{mm}$. The frame was sanded wet with cushioned sanding pads to remove abrasive material attached to the surface after cutting. 


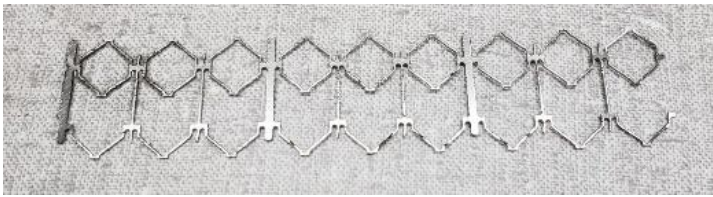

Figure 4. Stent frame cut using the OMAX waterjet

Figure 5 is showing the leaflets and fabric skirting were both made from the same synthetic material. A nylon ripstop fabric was chosen for its water resistance, tear resistance, flexibility, and low cost. Ripstop is also extremely thin; this type of fabric would not hinder the TAVR's crimping ability. Using Solidworks, a simplified leaflet design was created using a circular geometry and a leaflet graft sizing reference [18]. The sizing reference described the grafts as semicircular with a diameter $10-15 \%$ the size of the device's diameter; this basic shape was kept and small tabs were added near the free edge to aid in attachment. A circular shape was cut and folded into a semicircle to create a sturdier leaflet with a free edge that would not fray.

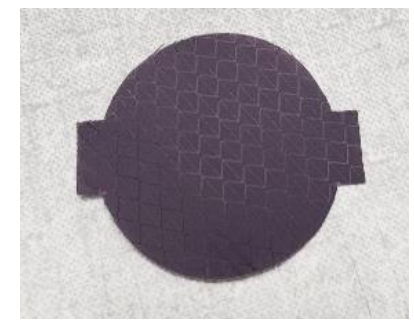

Figure 5. Synthetic leaflet cut from nylon ripstop using a Cricut fabric cutter

Figure 6 is showing the fabric skirting pattern was designed so the fabric could be folded over the frame's struts and secured to itself. The design is a simple rectangular shape the same length as the frame with cuts along the top to allow the fabric to be folded over the struts. There is extra length at the bottom of the pattern so the entire bottom edge could be folded up and secured between the lower cells. Both the leaflets and skirting were cut using a Cricut Maker, a consumer CNC fabric cutting machine. The type of material was set to lightweight fabric and the tool used was the rotary blade. The fabric was applied to the adhesive mat supplied with the machine and patterns were cut within seconds.

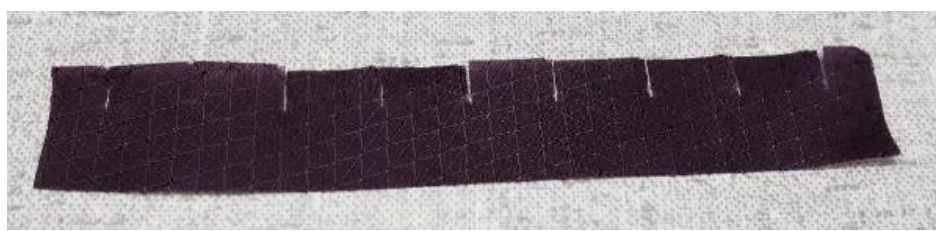

Figure 6. Fabric skirting cut from nylon ripstop using a Cricut fabric cutter

Typically, valve construction would consist of a 1-2 hours of suturing by hand. To reduce time and skill needed to complete a valve, Loctite waterproof fabric glue was used in substitution. The stent frame was carefully aligned on top of the fabric skirting, and each flap was folded over a strut and glued into place using a toothpick. The bottom of the skirting was folded over the bottom struts and glued to itself. The leaflets were glued down in the center of the circular shape to keep the free edge flat and along the circumference to keep them closed. They were then attached to the fabric skirting using the thicker struts as a guide and the tabs at the edge of each leaflet were glued to the adjacent leaflet. Construction of the device was reduced to approximately 30-40 minutes. 


\section{RESULTS AND ANALYSIS}

This processs began with the frame of the stent. Laser cutting and 3D printing were more expensive options compared to the waterjet. It took multiple iterations of cutting to refine the OMAX waterjet settings to cut the frame accurately at size. The first cut was made at $125 \%$ of the desired size. The following cuts involved a frame with simplified geometry because of the limitations of the waterjets cutting abilities. A revision to the stent frame included wider geometries and thicker struts; we also changed the waterjet settings to achieve the final stent frame presented here. Those first cutting attempts were welded into shape but left significant burn marks on the surface of the frame and the rough weld spots meant we needed a more refined welding method for the delicate frame. We used these frames to determine methods of fabric attachment. Traditionally, fabric attachment involves hundreds of individual stitches done by hand. Trying to do this on a frame that was already welded into its cylindrical shape proved to be extremely difficult and inefficient. Therefore, the easiest assembly of the device included an attachment method using glue instead of stitches and attachment of fabric before any welding was done (see Figure 7 and Figure 8). Table 2 is showing cost of supplies.

Table 2. Cost of supplies

\begin{tabular}{lll}
\hline Description & Provider & Price Per Unit \\
\hline Highly Corrosion-Resistant 316 Stainless Steel Sheet, 2" x 5 Feet, 0.015" Thick & McMaster-Carr & $\$ 25.98$ \\
1.3 Oz MTN XL Hybrid Ripstop Nylon 6.6 & Ripstop By the Roll & $\$ 8.95$ \\
Cricut Maker Machine & Cricut & $\$ 369.99$ \\
Loctite 1 fl oz Vinyl Fabric \& Plastic Flex Adhesive & Target & $\$ 2.99$ \\
Cushioned Sanding Pad Assortment, 9 Pieces & McMaster-Carr & $\$ 12.18$ \\
& Total & $\$ 420.09$ \\
\hline
\end{tabular}

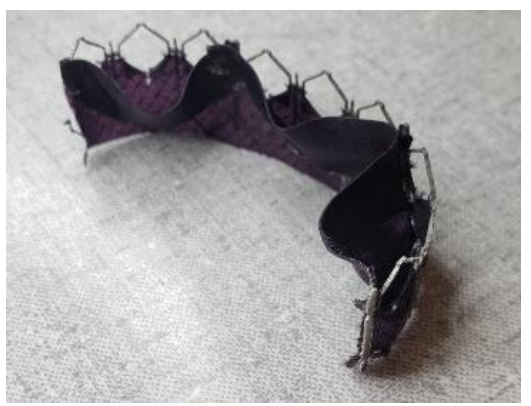

Figure 7. Final assembly of the device prototype

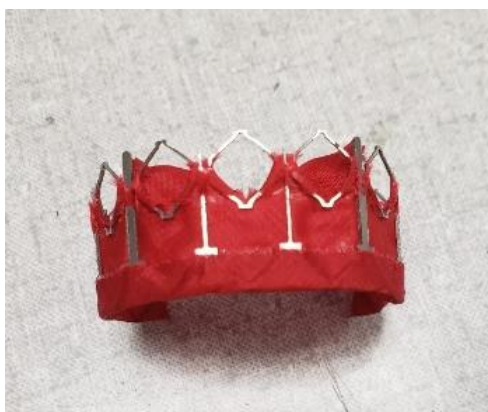

Figure 8. Second prototype with view of skirting attachment

\section{CONCLUSION}

Further experimentation is needed to define a welding method that will not damage the fabric that is already attached to the frame. There are no methods for crimping these prototypes other than building a crimper or obtaining one from medical personnel. Implantation of the device into a simulated aortic valve could produce the necessary flow data to confirm functionality. This would be an assessment not only of the frame's crimping and expansion ability but also the fabric's quality. Fabric was chosen simply for its availability and price, but if coaptation of the valve and proper flow dynamics are not achieved, the material could easily be replaced. The fabric type and attachment methods need to be assessed for paravalvular leaking, valvular regurgitation, and proper coaptation. The completion of this research could result in the creation of a new bench-top training method for TAVR implantation trainees or provide a means of validation for TAVR research involving computer modeling and simulations.

\section{REFERENCES}

[1] R. L. J. Osnabrugge, et al, "Aortic stenosis in the elderly: disease prevalence and number of candidates for transcatheter aortic valve replacement: a meta-analysis and modeling study," Journal of the American College of Cardiology, vol. 62, no. 11, pp. 1002-1012, 2013.

[2] A. Horne, et al., "Transcatheter aortic valve replacement: Historical perspectives, current evidence, and future directions," American Heart Journal, vol. 168, no. 4, pp. 414-423, 2014. 
[3] A. Kheradvar, et al., "Emerging Trends in Heart Valve Engineering: Part II. Novel and Standard Technologies for Aortic Valve Replacement," Annals of Biomedical Engineering, vol. 43, no. 4, pp. 844-857, 2014.

[4] S. K. Kodali, et al., "Two-year outcomes after transcatheter or surgical aortic velve replacement," New England Journal of Medicine, vol. Vol. 366, no.18, pp. 1686-1695, 2012.

[5] Détaint, L. Lepage, D. Himbert, E. Brochet, D. Messika-Zeitoun, B. Iung, and A. Vahanian, "Determinants of significant paravalvular regurgitation after transcatheter aortic valve implantation," JACC: Cardiovascular Interventions, vol. 2, no. 9, pp. 821-827, 2009.

[6] O. M. Rotman, M. Bianchi, R. P. Ghosh, B. Kovarovic, and D. Bluestein, "Principles of TAVR valve design, modelling, and testing," Expert Review of Medical Devices, vol. 15, no. 11, pp. 771-791, 2018.

[7] A. Hosny, et al, "Pre-procedural fit-testing of TAVR valves using parametric modeling and 3D printing," Journal of Cardiovascular Computed Tomography, vol. 13, no. 1, pp. 21-30, 2019.

[8] Q. Wang, E. Sirois, and W. Sun, "Patient-specific modeling of biomechanical interaction in transcatheter aortic valve deployment," Journal of Biomechanics, vol. 45, no. 11, pp. 1965-1971, 2012.

[9] B. Rosa, et al., "A low-cost bioprosthetic semilunar valve for research, disease modelling and surgical training applications," Interactive CardioVascular and Thoracic Surgery, vol. 25, no. 5, pp. 785-792, 2017.

[10] B. Rosa, Z. Machaidze, M. Mencattelli, S. Manjila, et al., "Cardioscopically guided beating heart surgery: paravalvular leak repair," The Annals of Thoracic Surgery, vol. 104, no. 3, pp. 1074-1079, 2017.

[11] G. Fagogenis, et al, "Autonomous robotic intracardiac catheter navigation using haptic vision," Science Robotics, vol. 4, no. 29, pp. 1-12, 2019.

[12] W. D. Buhr, et al, "Impairment of pericardial leaflet structure from balloon-expanded valved stents," The Journal of Thoracic and Cardiovascular Surgery, vol. 143, no. 6, pp. 1417-1421, 2012.

[13] O. M. Rotman, M. Bianchi, R. P. Ghosh, B. Kovarovic, and D. Bluestein, "Principles of TAVR valve design, modelling, and testing," Expert Review of Medical Devices, vol. 15, no. 11, pp. 771-791, 2018.

[14] B. Janci and M. L. Zoler, "TAVR Wallops SAVR in cost-effectiveness for intermediate-risk patients" Vascular Specialist, [Online]. O4-Dec-2018. Available: https://www.mdedge.com/vascularspecialistonline/article/150986/interventional-cardiology-surgery/tavr-wallopssavr-cost.

[15] Edwards Lifesciences "Edwards SAPIEN XT Transcatheter Heart Valve with the Ascendra Delivery System ," $\begin{array}{llll}\text { accessdata.fda.gov, } \quad \text { May-2014. } & \text { [Online]. }\end{array}$ https://www.accessdata.fda.gov/cdrh_docs/pdf13/P130009d.pdf.

[16] E. L. Videos, "Edwards SAPIEN XT Video," YouTube, 26-Mar-2015. [online]. Available:https://www.youtube.com/watch?v=Lcsw6y21b2o.

[17] I. Miraoui, M. Boujelbene, and E. Bayraktar, "Analysis of roughness and heat affected zone of steel plates obtained by laser cutting,” Advanced Materials Research, vol. 974, pp. 169-173, 2014.

[18] P. E. Hammer and P. J. D. Nido, "Guidelines for sizing pericardium for aortic valve leaflet grafts," The Annals of Thoracic Surgery, vol. 96, no. 1, pp. e25-e27,2013.

\section{BIOGRAPHIES OF AUTHORS}

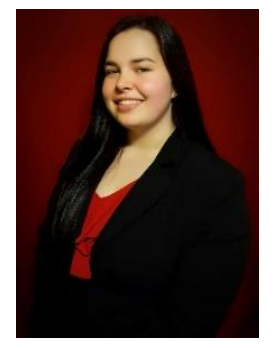

Angelique Oncale has her Master of Science in Systems Technology from the University of Louisiana at Lafayette, College of Engineering. Her areas of research interest are Design for Manufacturing, Computer Aided Design, and Medical Technology. She is currently employed as and automation engineer at Noble Plastics in Grand Coteau, Louisiana.

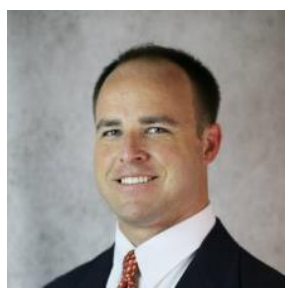

Charles Taylor, Ph.D., is an Assistant Research Professor of Engineering at College of Engineering of Louisiana State University and A\&M College. His areas of research interest are the development of safety, risk and reliability practices for medical devices targeting the cardiovascular system. He has obtained degrees in bioengineering (BS) and biomedical engineering $(\mathrm{PhD})$ 

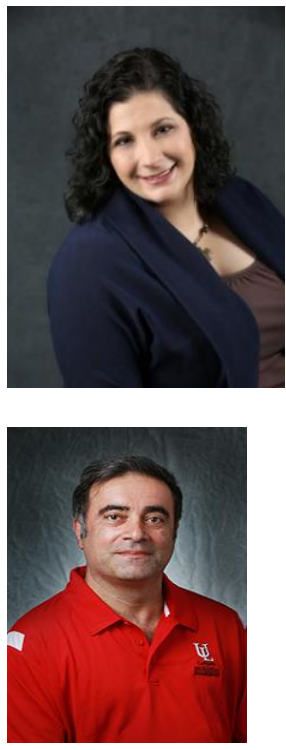

Erika Louvier has her Master of Science in Systems Technology from the University of Louisiana at Lafayette, College of Engineering. Her areas of research interest are Teaching, Computer Aided Design, Metal Technology, and Manufacturing. She is currently coordinator of Industrial Technology at South Louisiana Community College.

G. H. Massiha, Ph.D., is a Louisiana Board of Region Professor of Engineering and Systems Technology graduate coordinator at the University of Louisiana at Lafayette, College of Engineering. His areas of research interest are alternative energy, robotics, and automation manufacturing. 